\title{
Experimental equipment for measuring of rotary air motors parameters
}

\author{
Lukáš Dvořák ${ }^{1, *}$, Kamil Fojtášek ${ }^{2}$, Vojtěch Řeháček ${ }^{3}$ \\ 1,2,3 VŠB-Technical University of Ostrava, Faculty of Mechanical Engineering, Department of Hydrodynamics and Hydraulic Equipment, \\ 17. listopadu 15/2172, Ostrava 70833, Czech Republic
}

\begin{abstract}
In the article the construction of an experimental device for measuring the parameters of small rotary air motors is described. Further a measurement methodology and measured data processing are described. At the end of the article characteristics of the chosen air motor are presented.
\end{abstract}

\section{Introduction}

Rotary pneumatic motors can be divided into several categories by motor design. In this case we can divide the rotary pneumatic motors in vane, axial and radial piston, gear and turbine designs, Fig. 1.

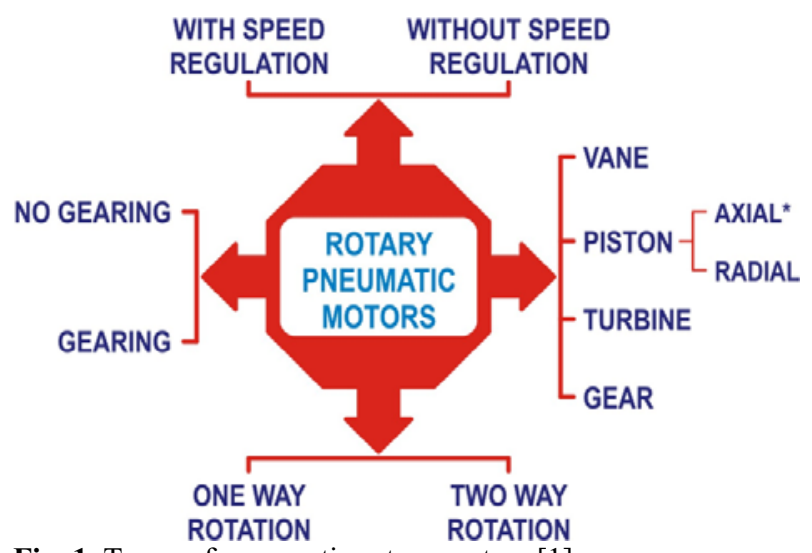

Fig. 1. Types of pneumatic rotary motors [1]

The objects of our research were mainly small radial piston motors with power up to $500 \mathrm{~W}$ and nominal speed up to $1000 \mathrm{~min}^{-1}$. An example of design of these motors is shown in Fig.2.

During the rotary air motors characteristics measuring it is necessary to determine the following parameters: an inlet pressure and eventually an outlet pressure, a motor torque, a rotation speed and an air consumption. The processing the measured data is described below. The result of measurements is the rotary motor characteristic, which is mainly a torque and power dependence on a rotational speed, Fig. 3. This characteristic may be complemented by an air consumption and an efficiency, this is then called a complex characteristic of the rotary motor.

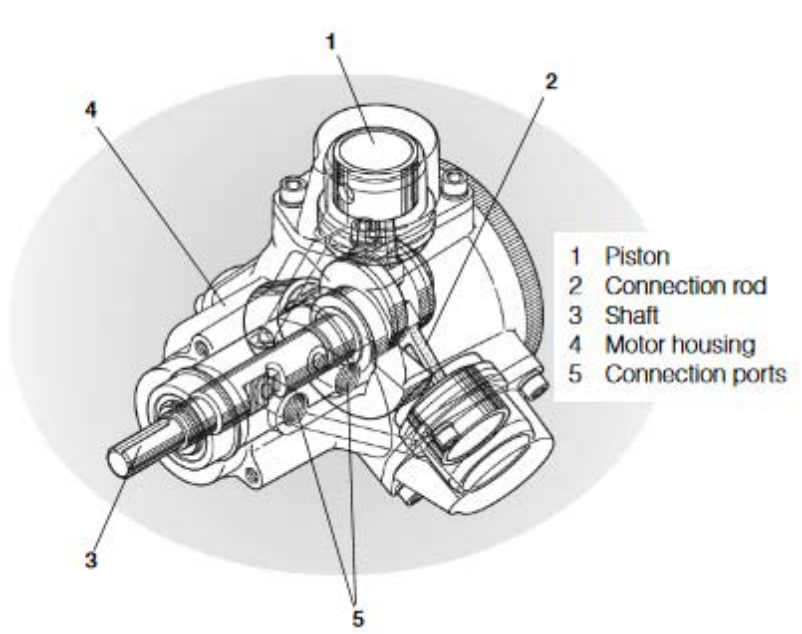

Fig. 2. Radial piston air motor [2]

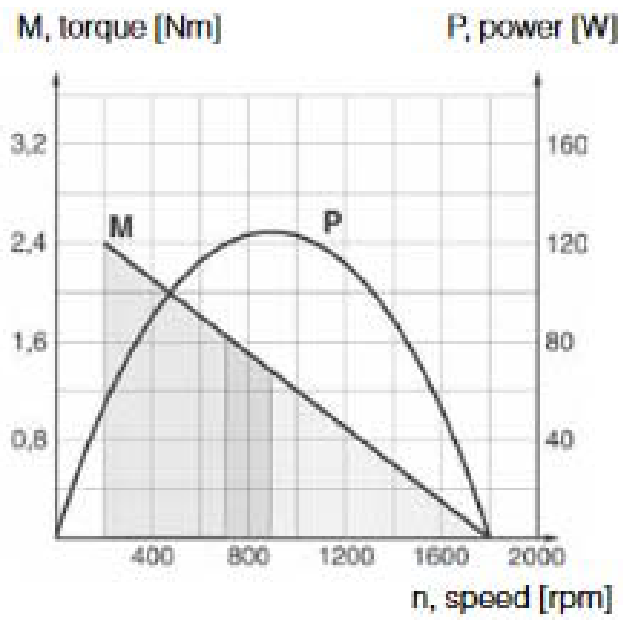

Fig. 3. Torque and power characteristics of motor [2]

*Corresponding author: lukas.dvorak@vsb.cz 


\section{Test equipment}

During the measurement of rotary motors it is necessary to change the load of the output shaft continuously. This can be achieved by some types of brakes. Table 1 provides an overview of possible ways of brake implementation. The values in the table show that suitable break for the motors with power up to $500 \mathrm{~W}$ is a friction brake. Due to its low power and simplicity of design a bicycle break has been chosen. Specifically type-ZEE BR-M640 from Shimano in combination with disc SM-RT 66 with a diameter of $160 \mathrm{~mm}$ was chosen. According to the producer the brake was tested for speeds up to $1350 \mathrm{~min}^{-1}$ and guaranteed braking power is $800 \mathrm{~W}$. This brake therefore fully complies with our requirements.

It was also necessary to choose sensors. To measure a torque the sensor T22 / 50 from HBM with a measuring range of $+/-50 \mathrm{Nm}$ was chosen. Furthermore, the pressure sensor PR 15 with a measuring range of -1 to 6 bar, the speed sensor DS 03 and the recording device M5050 ware chosen, all made by company Hydrotechnik. The flow measurement was realized by the sensor SD 6000 from IFM elekrtotechnik with measuring range $4-1250 \mathrm{dm}^{3} \cdot \mathrm{min}^{-1}$ (ANR). A frame to which were mounted all the necessary parts was also designed and built. The device is shown in Fig. 4, a circuit diagram is in Fig. 5.

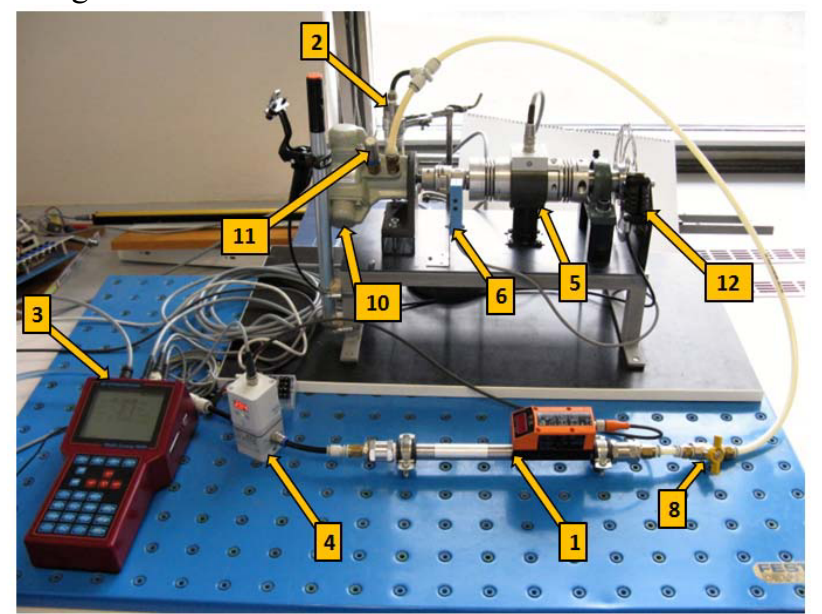

Fig. 4. Test equipment, 1 - flowmeter, 2 - pressure sensor, 3 - recording device, 4 - reduction valve, 5 - torque sensor, 6 - speed sensor, 7 - FRL unit, 8.9 - ball valve, 10 - pneumatic rotary motor, 11 - silencer, 12 - disc brake

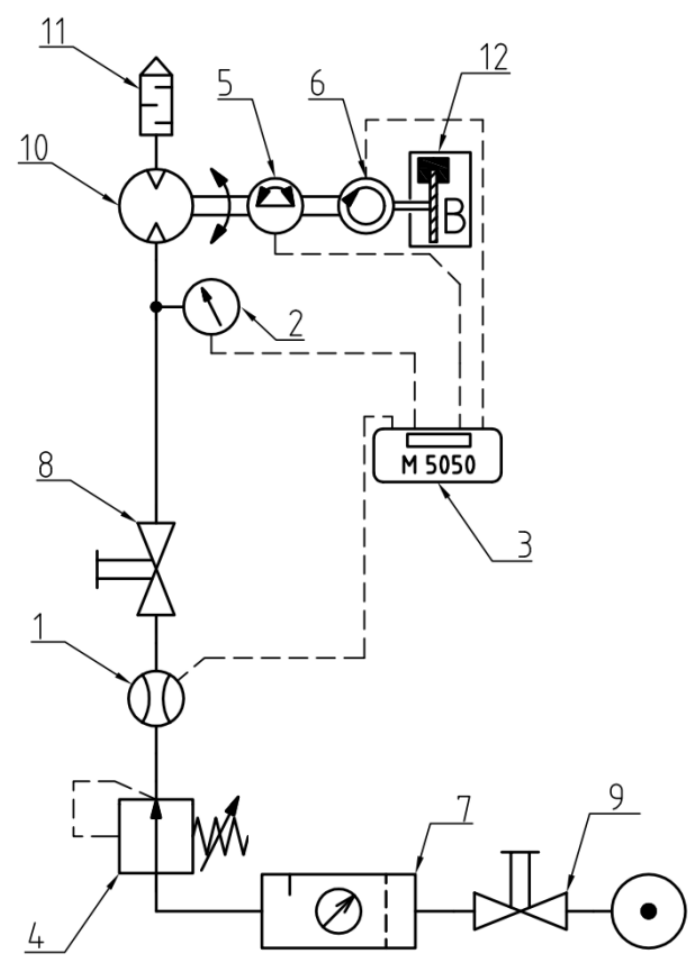

Fig. 5. Diagram of the test equipment (the description is the same as in Fig. 4)

\section{Measurement methodology and measured data processing}

The basic requirement for the measurement is to keep a constant pressure at the inlet of the motor. After the first few tests it was proved that the mechanically controlled pressure reducing valves are not suitable for this application. Therefore, in the subsequent measurements the pressure regulation was realized by proportional pressure valve VPPE-3-1-1 / 8-10-010-E1 made by Festo. By selecting the control voltage the measurements ware then carried out at a pressure level of 3, 4, 5 and 6 bar.

At each pressure level the torque was increased using the friction brake and after each change a record of all measured variables (pressure - $p$, torque - $M$, speed $-n$, flow rate $Q_{N}$ ) was made for 3 seconds with sampling period of 0.1 second. From the measured values the mean values were calculated. These were directly plotted into the graph, or were used to calculate the power $P$, the overall efficiency $\eta$ and specific consumption $\bar{m}$. An equation for the calculation of individual parameters is shown in equations 1 to 3 .

Table 1. Types of brakes

\begin{tabular}{|l|c|c|c|}
\hline \multirow{2}{*}{ Brake type } & \multicolumn{3}{|c|}{ Range of parameters } \\
\cline { 2 - 4 } & Power $[\mathrm{kW}]$ & Torque $[\mathrm{Nm}]$ & Rotation speed $\left[\mathrm{min}^{-1}\right]$ \\
\hline Elektrodynamometr & $3-800$ & $20-8000$ & $300-3000$ \\
\hline Hydrodynamic brake & $2-1000$ & $10-6000$ & $200-10000$ \\
\hline Hydrostatic brake & $0.5-50$ & $1-100$ & $100-8000$ \\
\hline Friction brake & $0.1-5$ & $0.5-50$ & $10-2000$ \\
\hline
\end{tabular}


The motor mechanical power on the output shaft can be calculated from the torque and speed

$$
P=\frac{2 \cdot \pi \cdot n \cdot M}{60} \quad[W]
$$

where $M$ is torque $[\mathrm{Nm}]$ and $n$ is speed $\left[\mathrm{min}^{-1}\right]$.

The motor overall efficiency is the ratio of mechanical output power to pneumatic input power. Due to the volume flow rate dependence on the pressure, it is necessary to recalculate the flow rate to the level of working pressure.

$$
\eta=\frac{P}{p \cdot Q_{p}}
$$

In the equation $P$ is power $[\mathrm{W}], p$ working pressure $[\mathrm{Pa}]$ and $Q_{p}$ is volume flow rate of compressed air $\left[\mathrm{m}^{3} \cdot \mathrm{s}^{-1}\right]$

Specific air consumption is air consumption related to output power. In this case, it is necessary to use flow rate recalculated to normal atmospheric conditions (ANR atmospheric normal reference).

$$
\bar{m}=\frac{Q_{N}}{P} \quad\left[d m^{3} \cdot \min ^{-1}(A N R) \cdot W^{-1}\right]
$$

In the equation $P$ is power $[W]$ and $Q_{N}$ is air consumption $\left[\mathrm{dm}^{3} \cdot \mathrm{min}^{-1}(A N R)\right]$

\section{Measurement results}

Fig. 6 shows the torque characteristic of the measured motor. The torque significantly decreases from a maximum value at zero speed (starting torque). The value of the starting torque is depending on the size of the pressure. At the inlet pressure of 3 to 6 bar the torque varies from 2 to $3.8 \mathrm{Nm}$. From the course of the power in Fig. 7 it is evident a parabolic shape of characteristic, which is typical for rotary pneumatic motors.

Table 2 shows the maximum power values at different working pressures. From the values it is obvious that the maximum power is achieved in the range of revolutions from 1100 to $1200 \mathrm{~min}^{-1}$.

Table 2. The maximum measured power

\begin{tabular}{|c|c|c|}
\hline$p[$ bar $]$ & $n\left[\mathrm{~min}^{-1}\right]$ & $P[W]$ \\
\hline 3 & 1180 & 128 \\
\hline 4 & 1210 & 170 \\
\hline 5 & 1100 & 192 \\
\hline 6 & 1120 & 229 \\
\hline
\end{tabular}

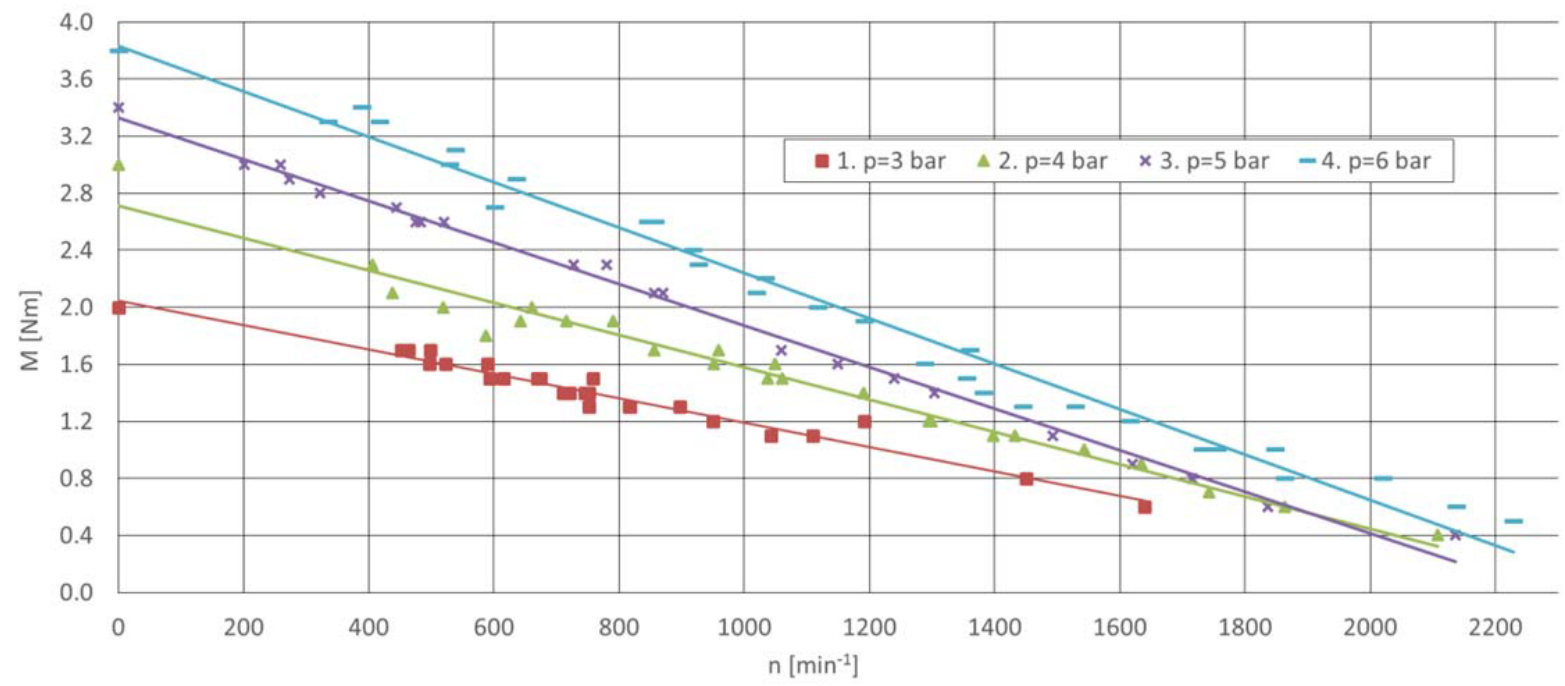

Fig. 6. Torque characteristic

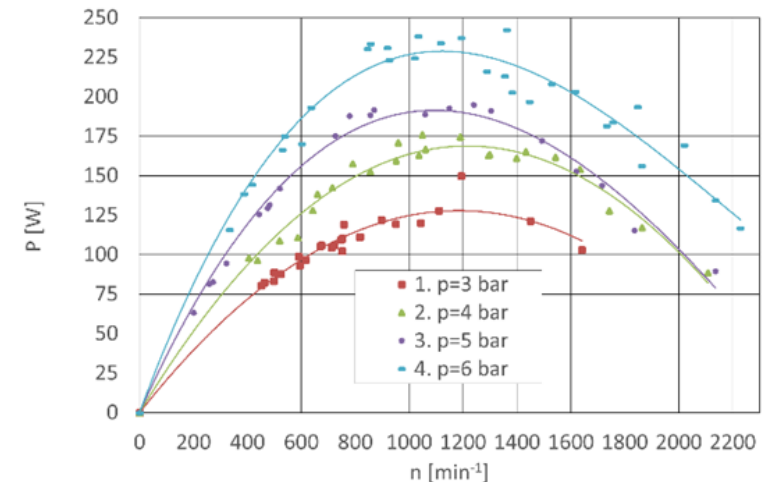

Fig. 7. Power characteristic

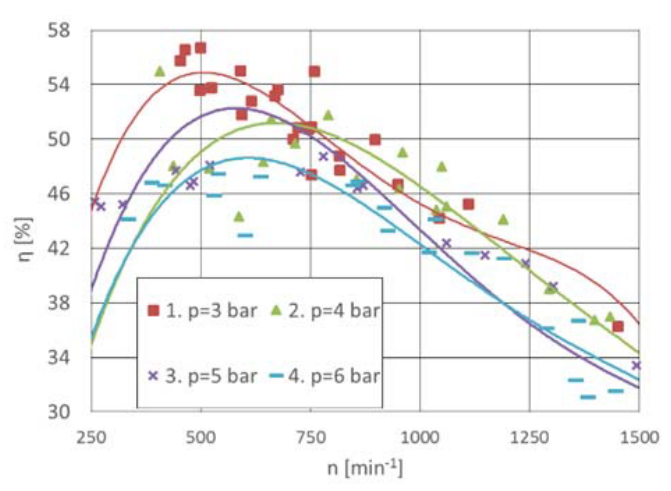

Fig. 8. Overall motor efficiency 
Fig. 8 shows the course of overall efficiency of the measured motor. The maximum efficiency for different pressure values is in the range of $48-55 \%$. These values are achieved in the speed range from 500 to $750 \mathrm{~min}^{-1}$.

From the above it is clear that the area of maximum efficiency is shifted in comparison with the area of maximum power to the lower speed. Generally, the optimum working range of the motor is located between maximum efficiency and maximum power. The maker states that the optimum range is from 700 to $900 \mathrm{~min}^{-1}$, which corresponds with the measured values.

\section{Conclusion}

The article described the measuring of basic characteristics of small rotary air motors. The device can be used for motors with power up to $500 \mathrm{~W}$. The equipment can be used further for measuring of the impact of speed regulation. The motor speed control can be easily realized with a throttle valve, Fig. 9. The valve can be connected into the circuit so that it regulate air flow on inlet to the motor (supply throttling) or some motor designs allows regulation on the outlet (outlet throttling). Throttle valve and its location affects the torque and power characteristics. Fig. 10 and Fig. 11 shows the measured characteristics for the different settings of throttle valve.

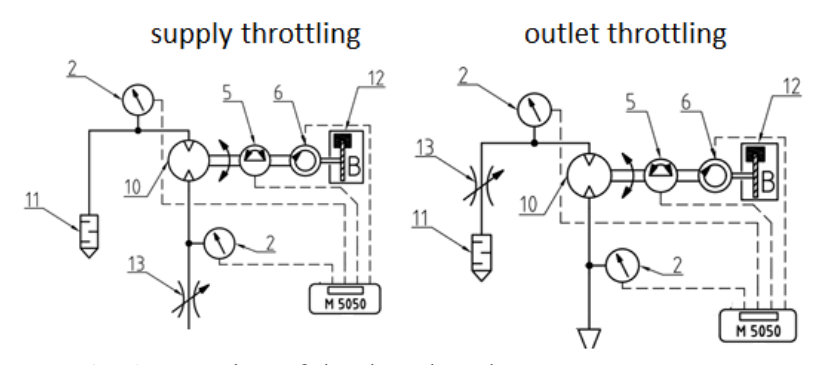

Fig. 9. Location of the throttle valve

\section{Acknowledgements}

This work was supported by the project SP2015/95 of VŠB-Technical University of Ostrava.

\section{References}

1. P.Tuleja. Application Possibilities of Rotary Pneumatic Drives Using. American Journal of Mechanical

Engineering. Vol.3 (2015). online:

http://pubs.sciepub.com/ajme/3/6/25/index.html

2. Rotary Actuators Catalogue. Online:

http://www.parker.com/literature/Pneumatics\%20Divisio n\%20Europe/PDE-

Documents/Rotary Actuators Platform Catalogue PDE 2613TCUK.pdf

3. J. Kopáček: Pneumatické mechanismy (1998)

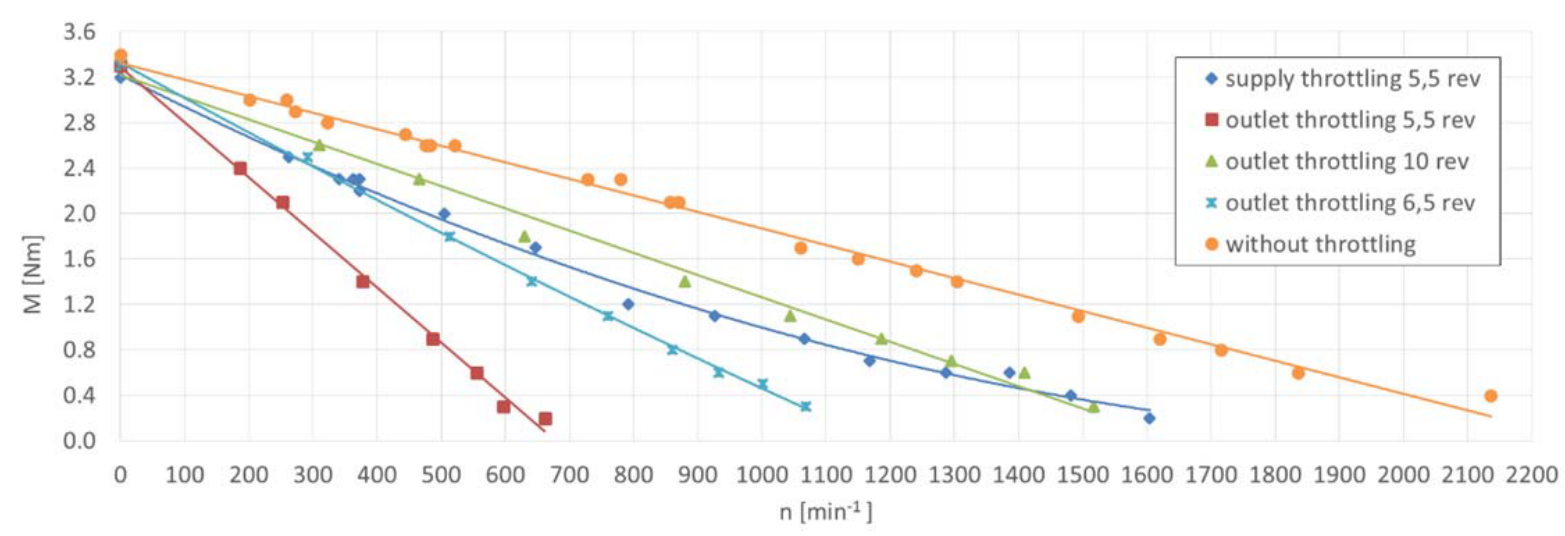

Fig. 10. Torque characteristic - influence of the throttling

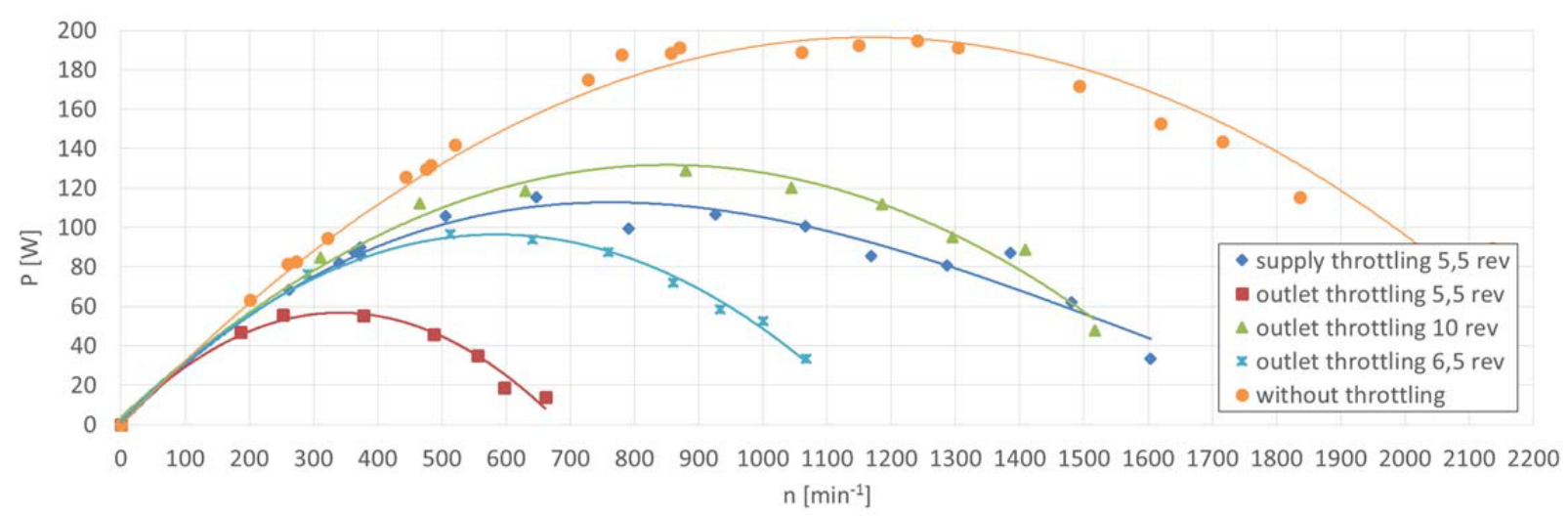

Fig. 11. Power characteristic - influence of the throttling 